\title{
Asentar su autoridad: banquetas en el Grupo B de Río Bec (Campeche, México)
}

Marie-Charlotte Arnauld y Alfonso Lacadena

\section{(2) OpenEdition}

\section{Journals}

Edición electrónica

URL: https://journals.openedition.org/jsa/2613

DOI: $10.4000 /$ jsa. 2613

ISSN: 1957-7842

Editor

Société des américanistes

\section{Edición impresa}

Fecha de publicación: 5 enero 2004

Paginación: 203-222

ISSN: 0037-9174

\section{Referencia electrónica}

Marie-Charlotte Arnauld y Alfonso Lacadena, «Asentar su autoridad: banquetas en el Grupo B de Río Bec (Campeche, México)», Journal de la Société des américanistes [En línea], 90-1 | 2004, Publicado el 05 enero 2009, consultado el 04 septiembre 2022. URL: http://journals.openedition.org/jsa/2613 ; DOl: https://doi.org/10.4000/jsa.2613 


\title{
ASENTAR SU AUTORIDAD : BANQUETAS EN EL GRUPO B DE RÍO BEC (CAMPECHE, MÉXICO)
}

\author{
Marie-Charlotte ARNAULD * y Alfonso LACADENA **
}

\section{INTRODUCCION}

En marzo y abril de 2003, las excavaciones del edificio 6N2 de Río Bec (Campeche, México), vecino del famoso edificio B dotado de dos torres, revelaron que cada uno de los tres aposentos centrales contenía una banqueta de mampostería. En términos generales, la configuración de este espacio es idéntica a la del mencionado edificio $\mathrm{B}$, ó $6 \mathrm{N1}$ en la nomenclatura del proyecto arqueológico Río $\mathrm{Bec}^{1}$. $6 \mathrm{~N} 1$ y $6 \mathrm{~N} 2$ presentan morfologías y rasgos arquitectónicos que los designan como residencias de la élite maya clásica (Michelet et al. 2003, Op. V, pp. 9-22). En el arreglo interior habitual de este tipo de estructuras, al menos de las que muestran cierto grado de elaboración, las banquetas de mampostería son muy frecuentes en las tierras bajas mayas, y bien distribuidas desde el Clásico Tardío hasta la Conquista (600-1540 d.C., véase Noble 1999). Lo sorpredente en el caso de las tres banquetas de 6 N2 es que presentan no sólo soportes esculpidos y pintados policromados, sino que también el canto de su parte delantera, o frente, está pintado con unos textos glíficos en policromía.

A continuación, presentaremos una breve descripción de las banquetas en su contexto arquitectónico, así como de su decoración, tanto en sus elementos iconográficos como en sus componentes epigráficos, con una lectura de estos últimos. Intentamos un análisis comparativo preliminar de dichas banquetas y de su decoración, para proponer finalmente algunas conclusiones tentativas en cuanto al significado social de estos elementos en el marco de la residencia $6 \mathrm{~N} 2$, vecina de la residencia $6 \mathrm{Nl}$ (a $7 \mathrm{~m}$ de distancia).

\section{DESCRIPCION DE LAS BANQUETAS}

El edificio $6 \mathrm{~N} 2$ presenta, al igual que $6 \mathrm{~N} 1$, una división en tres componentes, típica de la arquitectura Río Bec (Figura 1) : un cuerpo central abierto hacia el

\footnotetext{
* UMR 8096 du CNRS, Maison de l'archéologie et de l'ethnologie, Nanterre [arnauld@mae.uparis $10 . \mathrm{fr}]$.

** Universidad Complutense, Madrid [lorengar@idecnet.com].

Journal de la Société des Américanistes, 2004, 90-1, pp. 203-222. CSociété des Américanistes.
} 


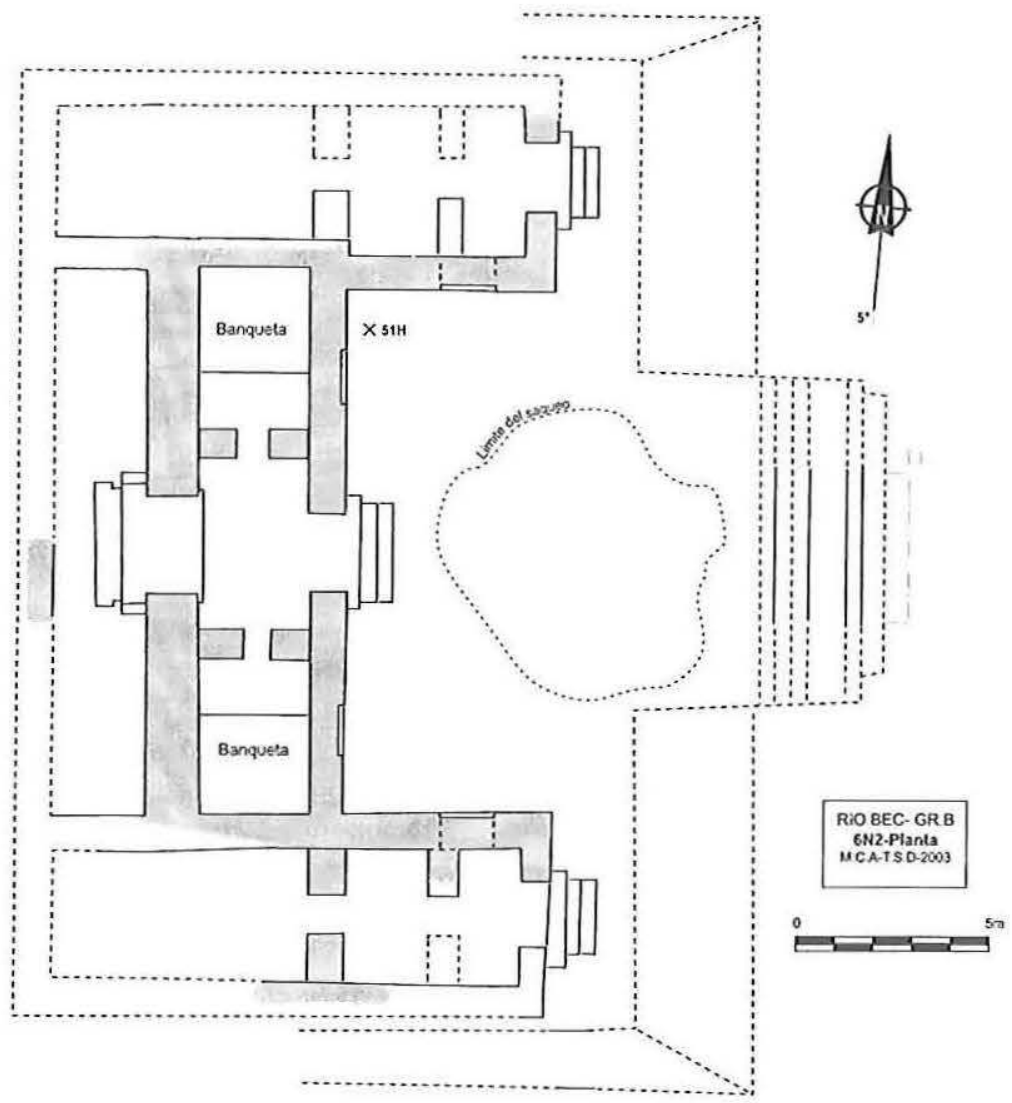

Fig. 1 - Planta del edificio 6N2, Grupo B, Río Bec (Levantamiento de Michelet, González, Arnauld ; dibujo de Saint-Dizier)

este (al igual que $6 \mathrm{~N} 1$ ) se combina con dos alas laterales norte y sur, que también abren hacia el este (a diferencia de $6 \mathrm{Nl}$ cuyas alas abren al norte y al sur). El cuerpo central consistió originalemente de dos salones paralelos de $14 \mathrm{~m}$ de longitud cada uno. En un momento dado, el salón anterior se dividió en tres, de tal modo que una especie de antecámara diera acceso a dos cuartos laterales, llamados " cuarto norte » $\mathrm{y}$ " cuarto sur », y al salón posterior. Las tres banquetas en las que se enfoca el presente trabajo ocupan los cuartos norte y sur y el salón posterior ; las tres datan de la construcción original. Las seis cámaras adicionales de las alas sur y norte (excavadas en 2004) carecen de este tipo de arreglo. Todos los espacios interiores (diez en total) fueron abovedados. Cabe señalar que también son presentes rasgos que generalmente indican una ocupa- 
ción doméstica : cortineros en las jambas de puertas, hoyos en los muros para estantería, un nicho en un muro del cuarto sur; por lo tanto, aparte de su probable significado sociopolítico, las banquetas decoradas tenían una sencilla función de cama en la noche y de sofá en el día.

Las dos banquetas de los cuartos sur y norte son idénticas (Figuras 2 y 3 ) : con dimensiones de $2.60 \mathrm{~m}$ de largo y $2.80 \mathrm{~m}$ de ancho, ocupan el $65 \%$ del espacio de cada cámara $\left(11\right.$ a $\left.12 \mathrm{~m}^{2}\right)$; tienen de 67 a $70 \mathrm{~cm}$ de altura sobre el piso estucado interior. Estucadas y conservadas enteramente de muro a muro, sufrieron daños ocasionados por la caída de la bóveda solamente en la parte delantera. Esta última la conforman tres grandes piedras talladas $(85-100 \mathrm{~cm}$ de ancho, $70 \mathrm{~cm}$ de largo y $19-20 \mathrm{~cm}$ de grosor). Soportaban estas piedras dos pequeños " pilares » rectangulares $(20 \times 20 \mathrm{~cm} ; 37 \mathrm{~cm}$ de alto), colocados en cada borde este y oeste, y dos columnillas en la parte media (36-38 $\mathrm{cm}$ de diámetro máximo, 29-34 cm de ancho en la parte de atrás, $32 \mathrm{~cm}$ de grosor y $37 \mathrm{~cm}$ de alto). De este modo existía un espacio vacío debajo de cada banqueta, que evoca los nichos comunes en banquetas mayas, aunque es mucho más grande $(2.33 \mathrm{~m}$ de ancho, $36 \mathrm{~cm}$ de alto, $60 \mathrm{~cm}$ de profundidad); en cada uno se encontraron tepalcates de grandes recipientes. Las piedras labradas que delimitan en el fondo este espacio vacío, los pilares y las columnillas reposan sobre un nivel de piedras talladas estucadas, en las que remata el piso del cuarto. La parte posterior de cada banqueta es de mampostería sólida, de piedras pequeñas y mortero de cal, y aguantó bien la caída del techo.

En cada banqueta, los pilares y el espacio vacío están estucados y pintados enteramente de rojo, los primeros con bandas verdes verticales en sus orillas y aristas (2 a $2,5 \mathrm{~cm}$ de ancho). El canto de las tres piedras delanteras - tallado esmeradamente en ligero bisel con arista superior redondeada por el repelloestá dividido en varios paneles por medio de bandas verticales pintadas de color azul claro sobre el estuco, conformando un friso este-oeste. Los dos paneles laterales este y oeste son rojos, bordeados arriba y abajo de dos bandas de color verde oscuro de $2 \mathrm{~cm}$ de ancho. Los paneles intermedios son pintados, desde el exterior hasta el centro,

- en la banqueta sur, primero de verde oscuro con glifos trazados en negro, luego de anaranjado con glifos trazados también en negro ; la parte central del canto está destruida por la caída de las piedras de bóveda ;

- en la banqueta norte, de verde oscuro (16 cm de largo) pintado sobre rojo, luego de verde oscuro ( $20 \mathrm{~cm}$ de largo) con dos glifos trazados en negro (fecha calendárica, véase más adelante), luego de azul (37 cm de largo) con dos glifos trazados en anaranjado ; más adelante, la decoración conservada es muy fragmentaria pero se notan figuras negras sobre verde y anaranjadas sobre azul ; las bandas de separación de paneles son azules con círculos o medio-círculos superpuestos de color anaranjado, pero otras son verdes y una anaranjada, para lograr contrastes. 


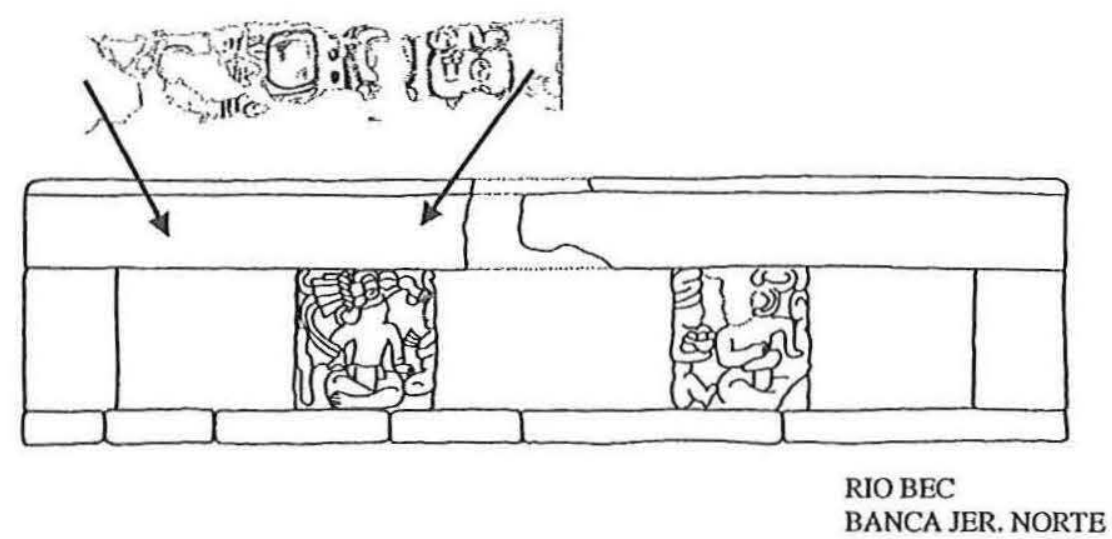

FIG. 2 - Elevación de la banqueta del cuarto norte de la estructura 6N2 (Lacadena)

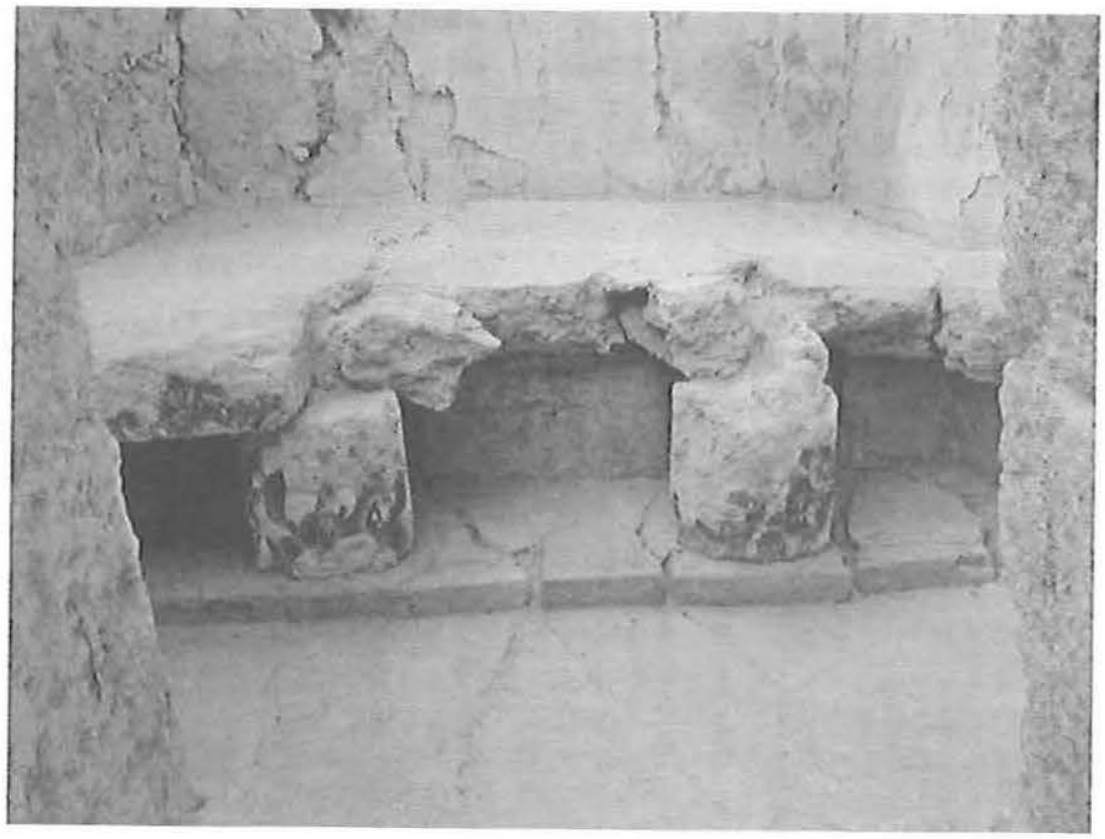

Fig. 3 - Foto de la banqueta del cuarto sur, 6N2 
Los cuatro soportes de las dos banquetas en forma de columnillas, están esculpidos en altorrelieve con motivos estucados y pintados de varios colores, habiéndose representado, en cada uno de ellos, un personaje ricamente ataviado con tocado complejo, sentado frente a otro de rango menor también sentado ; el primero está situado del lado exterior y el segundo del lado central, de tal modo que los personajes de rango menor fueron los más destruidos por las piedras de bóveda, mientras que los personajes de tocado complejo conservan más detalles. Pero los rostros fueron todos borrados con cuidado, posiblemente en el momento del abandono, ya sea por precaución (cancelando la representación personal), o bien por vandalismo.

Finalmente, el salón posterior tiene una superficie de $34.30 \mathrm{~m}^{2}$, de los cuales la banqueta $\left(\mathrm{n}^{\circ} 3\right)$ ocupa 32 , ya que el espacio sin banqueta se limita a los $2.2 \mathrm{~m}^{2}$ de entrada frente a la puerta ; más que una banqueta, se trata pues de un piso interior sobreelevado de $68 \mathrm{~cm}$ de altura, al cual se podía ascender por dos escalinatas laterales pequeñas, de dos gradas estucadas y pintadas de rojo (véase en K4549 la representación de una banqueta sobre soportes con escalera lateral de acceso). Sin embargo, se designa este arreglo como « banqueta oeste " porque la morfología de su frente fue similar a la de las banquetas norte y sur : es decir, una serie de piedras grandes pintadas, sostenidas por columnillas recubriendo un amplio espacio inferior vacío. Si bien aquí las columnillas desaparecieron, las piedras del frente fueron desarmadas y depositadas en los cuartos vecinos (tres en el cuarto sur y una en el cuarto central, o antecámara), donde las encontramos apoyadas contra los muros, sin protección alguna. Ya que no hay huella ni indicio de alguna acción violenta, se supone que los mismos habitantes desarmaron la banqueta en el momento del abandono de la estructura, quizás para no dejar a la vista de gente desconocida o enemiga los glifos y las figuras que decoraban su parte delantera. De los soportes de las piedras de orilla, sólo entonces quedan los dos pilares de las extremidades norte y sur $(40 \times 20 \mathrm{~cm} ; 46-47 \mathrm{~cm}$ de alto); el pilar norte todavía sostiene una piedra de orilla, la única que quedó in situ. Tomando en cuenta la posición y la medida de esta piedra y la longitud total de la banqueta medida entre las dos escalinatas laterales $(418 \mathrm{~cm})$, se considera que el frente en su conjunto estaba formado por dos piedras laterales de $42 \mathrm{~cm}$ de ancho cada una, apoyadas sobre los pilares, y tres piedras centrales de $110 \mathrm{~cm}$ de ancho, soportadas posiblemente por sólo dos columnillas. Espacio vacío inferior y pilares estaban pintados de rojo mientras que los cantos de las cinco piedras del frente llevaban pintura policromada en paneles separados por bandas verticales de color azul, de los que se conservan bastantes vestigios. Desconocemos el orden de las piedras y, por lo tanto, de los colores de bandas y paneles, pero la secuencia más probable sería rojo (piedra desaparecida), glifos negros sobre verde oscuro (piedras VC y VGAV), glifos negros sobre anaranjado y anaranjados sobre azul (AA), glifos negros sobre anaranjado (AN), y finalmente rojo (piedra norte in situ). 


\section{BREVE DESCRIPCION DE LA ICONOGRAFIA DE LAS BANQUETAS SUR Y NORTE}

Las columnas se encuentran esculpidas en altorrelieve, de unos $3 \mathrm{~cm}$ de profundidad. La técnica escultórica combinó el tallado de elementos en la superficie de la piedra, junto con acabados más detallados en estuco, que posteriormente se decoraron con pintura verde, roja, azul y anaranjada.

En la columnilla este de la banqueta sur (Figura 4), de izquierda a derecha, es decir de este a oeste, se divisa una entidad sobrenatural zoomorfa y dos personajes humanos sentados de perfil, a la manera oriental. De la entidad, sólo está representada la cabeza sin cuerpo, de perfil, mirando hacia el centro de la banqueta, pintada de colores rojo, anaranjado y verde : nariz larga encorvada, o más bien pico, ojo semi-circular, frente y tocado de dos partes, de las cuales la parte delantera es puntiaguda ; hay una excrecencia circular en la parte inferior de la frente cerca del ojo.

El personaje sentado del lado este lleva un tocado sencillo de forma rectangular, del cual cuelgan tres penachos largos de pluma, anchos, pintados de rojo. El torso aparece pintado de rojo y azul, con un pectoral sobre el pecho de forma ovalada con dos colgantes, pintado de azul, y una ancha faja de cintura pintada asimismo de azul ; los muslos aparecen cubiertos de una tela de colores azul y rojo. La mano derecha descansa sobre el piso. La mano izquierda está levantada como si el personaje estuviera haciendo un gesto acompañando a su palabra. Este personaje es claramente de rango superior en relación con el otro, por el penacho de plumas y la postura adoptada.

El personaje sentado frente al primero le presenta un objeto de forma rectangular que, por comparación con otras representaciones y por su superficie negra, bien podría ser un espejo. Lleva un tocado rectangular sencillo, rojo y azul, sin plumas, un colgante en forma de barra rectangular horizontal decorada de dos anchos puntos negros, un taparrabo azul con orilla marcada por tres líneas negras, posibles franjas ; el cuerpo está pintado de rojo.

En la columnilla oeste de la misma banqueta (Figura 5), la escena no es exactamente simétrica a la primera ya que la entidad sobrenatural no aparece en este caso, siendo reemplazada por un gran penacho de plumas voluminosas, verdes y anaranjadas, que sale del tocado - destruido - del personaje sentado del lado oeste. Este personaje tiene la piel de color rojo, un taparrabo y una cintura en faja de color azul así como un colgante de pecho de colores anaranjado y verde. Su posición es idéntica a la de su contraparte de la otra columna con la mano derecha levantada, tomando el objeto más alto del paquete que presenta el individuo que lo enfrenta.

De este último personaje sólo se conservan su cinturón en faja ancha de colores rojo, negro, anaranjado y verde, su taparrabo de color anaranjado con líneas verdes, su brazo derecho rojo que descansa sobre el muslo derecho también rojo. La mano (roja) sostiene una escudilla en la cual hay dos o tres objetos 


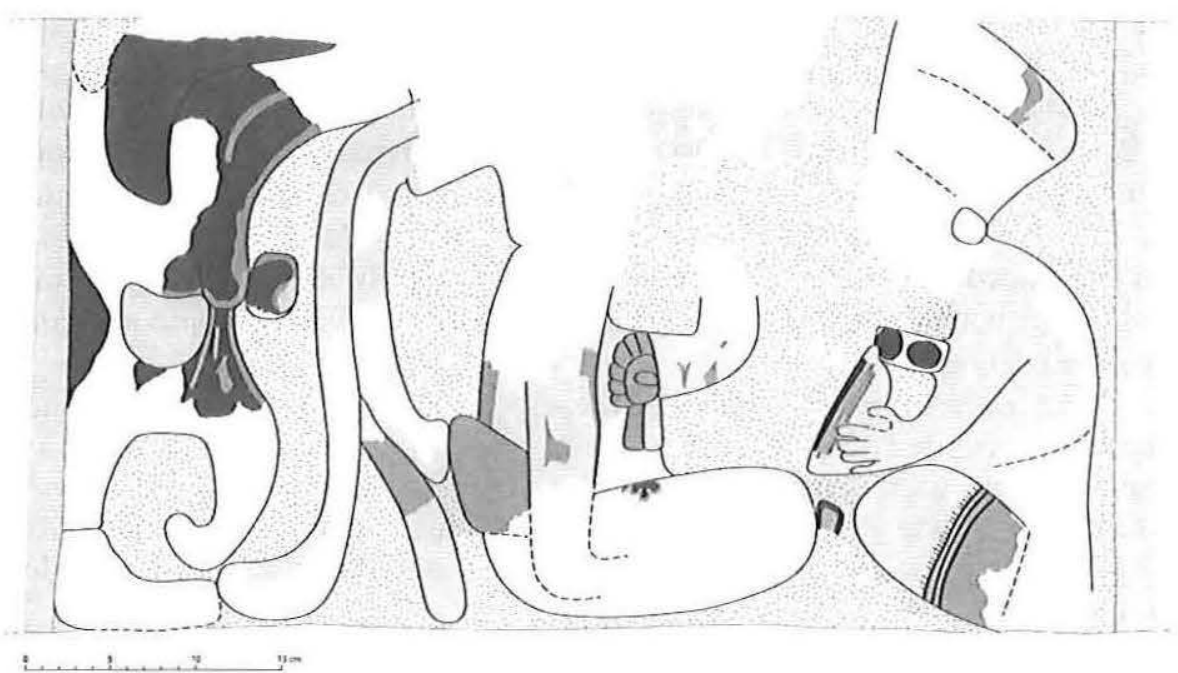

Fıg. 4 - Columnilla este de la banqueta sur, 6N2 (Levantamiento de Arnauld ; dibujo de Ávila)

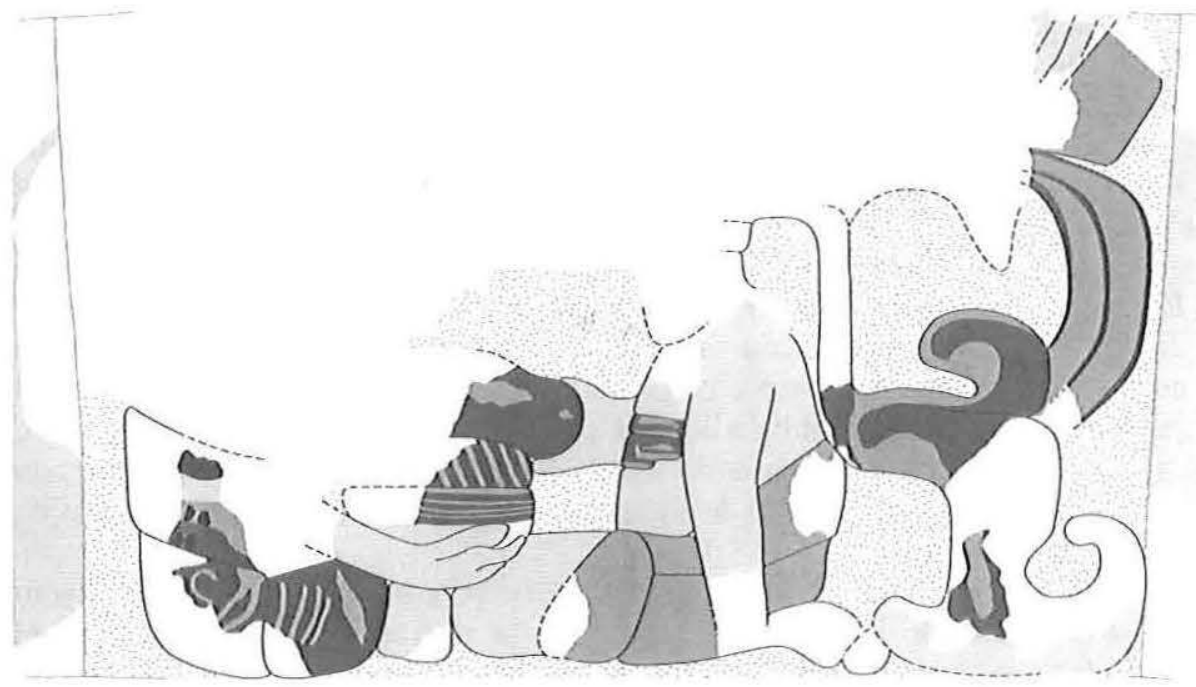

Fig. 5 - Columnilla oeste de la banqueta sur, $6 \mathrm{~N} 2$ (Levantamiento de Arnauld ; dibujo de Ávila) 
superpuestos, de color anaranjado decorados con líneas verdes ; podrían representar comida (¿ quizás tamales ?) o, debido a los colores idénticos al taparrabo, paños o pedazos de tejidos doblados.

En la columnilla este de la banqueta norte (Figura 6), la escena es parecida a la de la columnilla este del cuarto sur : entidad sobrenatural, personaje importante representado con otro personaje de rango inferior sentado de perfil frente a él. Pero hay tres diferencias que señalar : el cuerpo del personaje de rango superior queda de frente, con sólo la cabeza de perfil, su tocado parece más complejo y voluminoso y los colores casi no están conservados debido a la caída casi total del repello.

El ser sobrenatural tiene cabeza sin cuerpo, representada de perfil, mirando hacia el centro de la banqueta. Es la misma que la de la columnilla este de la banqueta sur : nariz larga curvada, o más bien pico (aunque no se ve su parte inferior, escondida detrás del brazo del personaje vecino), ojo semi-circular, tocado voluminoso con dos elementos altos, del cual el delantero es puntiagudo ; no hay excrecencia arriba del ojo.

El personaje sentado de frente lleva un tocado grande (i verde ?) cuyos detalles no se conservan, pero su extensión sugiere que no era diferente del tocado del personaje simétrico de la otra columnilla (véase más adelante). Lleva un taparrabo (verde) apenas marcado ; no se distingue colgante de pecho. La piel sería roja. Está sentado a la manera oriental, de frente. La mano izquierda queda aparentemente apoyada sobre el muslo izquierdo ; el cuerpo está un poco inclinado hacia la derecha y el brazo derecho está doblado con la mano a nivel del abdomen. La cara estaba mirando, de perfil, hacia el otro individuo.

Este segundo individuo presenta detalles mucho mejor conservados, lo que sugiere que el primer personaje ha sido intencionalmente dañado. Se trata claramente de un enano, quizás de piel roja. Está sentado con las piernas extendidas, anormalmente cortas y gruesas y por lo tanto lígeramente dobladas. El tocado es típico de los enanos, « gorra de punta » (verde) muy larga y doblada en tres o cuatro pliegues, con un especie de pequeño penacho de dos plumas cortas atado atrás, que parece como una imitación paródica del penacho del personaje importante. También lleva una orejera circular grande y una cintura en faja de buen espesor. Carga en la mano derecha un especie de recipiente con mango largo horizontal, lleno de algún material que forma una bola, de comida o de copal (incienso).

En la columnilla oeste de la banqueta norte (Figura 7), la escena es el exacto simétrico de la de la columnilla este, con la diferencia de que el enano es reemplazado por un jorobado. Aquí los detalles de los dos individuos representados se conservan bastante bien y el estado de preservación del individuo jorobado no parece ser mejor que el del personaje de rango superior. Sin embargo, poco se conserva de los colores. La entidad sobrenatural es idéntica a la de la otra columnilla, con una nariz encorvada más neta, verdadero pico de 


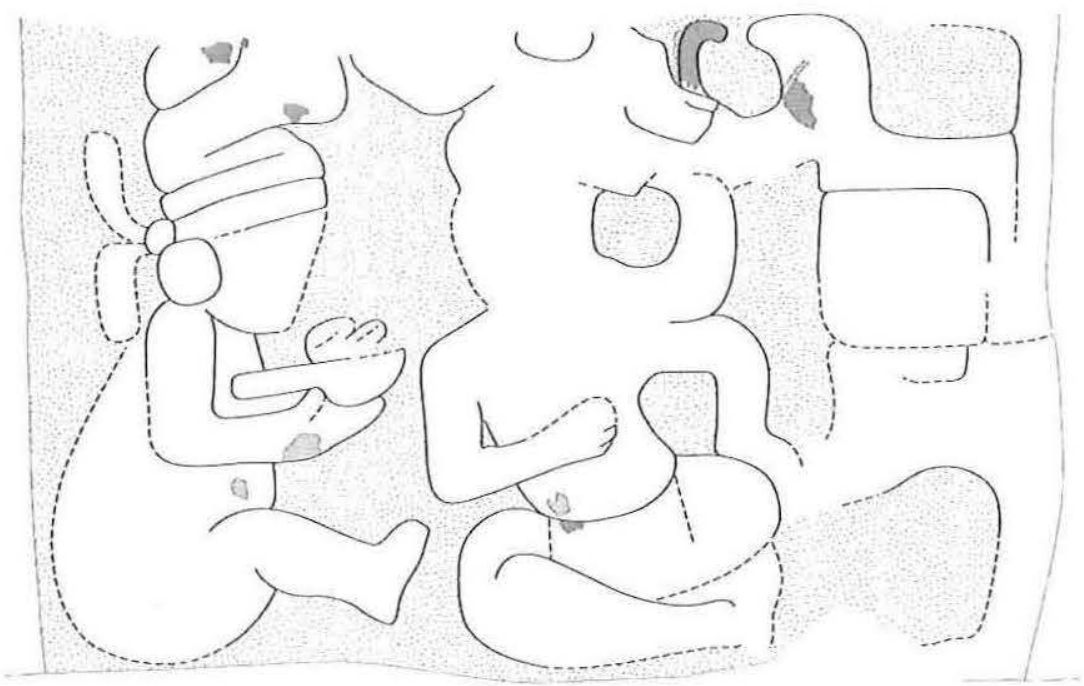

FIG. 6 - Columnilla este de la banqueta norte, 6N2 (Levantamiento de Arnauld ; dibujo de Ávila)

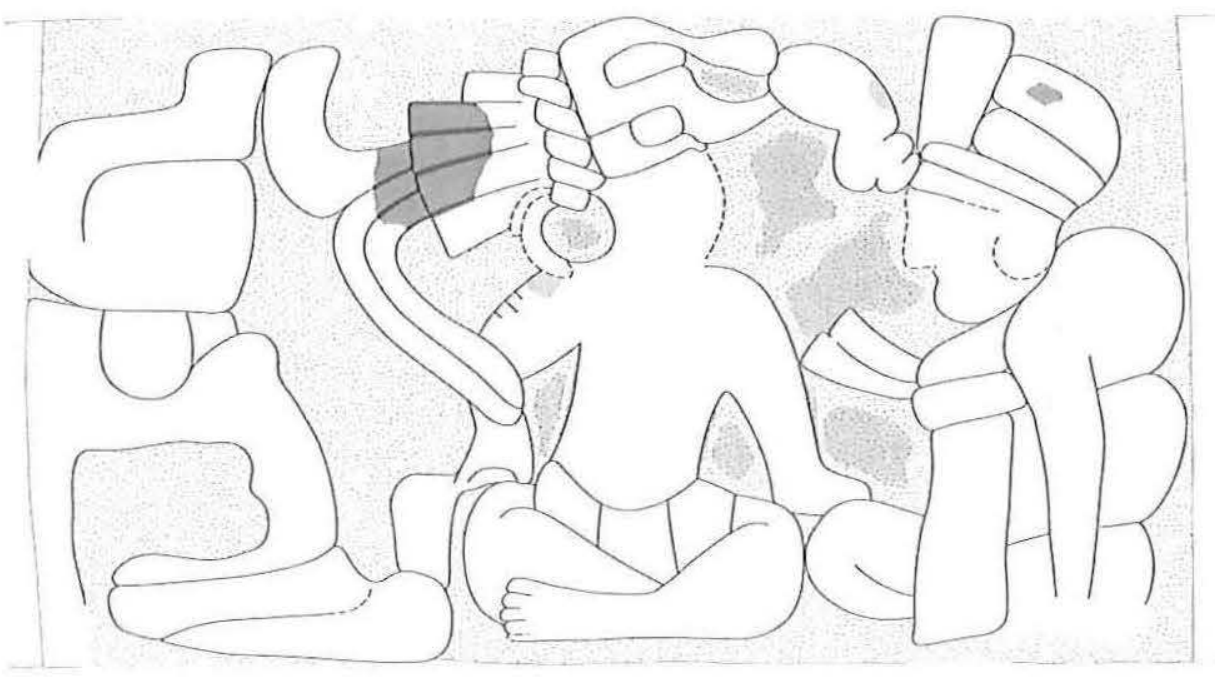

FIG. 7 - Columnilla oeste de la banqueta norte, 6N2 (Levantamiento de Arnauld ; dibujo de Ávila) 
pájaro. El ojo semi-circular es más grande ; se distingue algún elemento delante del ojo, aunque no es circular. La punta delantera del tocado también se ve claramente.

El personaje importante también está sentado de frente, a la manera oriental y lleva un tocado con una máscara frontal de ojo ovalado y nariz puntiaguda, así como varios penachos de plumas que salen de un elemento trenzado en forma de estera pop, símbolo de poder. Este individuo sólo lleva un taparrabo corto. La mano derecha, que agarra quizá un mosqueador de plumas, descansa sobre el muslo derecho, la mano izquierda quizás sobre la pierna del jorobado.

El jorobado lleva un tocado (azul) de cuatro pliegues superpuestos no muy diferente del tocado del enano, pero en la parte delantera éste tiene lo que podría ser un penacho de plumas rígidas verticales y otro penacho (¿ rojo ?) más flexible e inclinado hacia adelante. El jorobado también lleva orejera circular, aunque más pequeña que la del enano. Parece vestido de elementos de tejidos voluminosos, como hinchados sobre su cuerpo. Sentado de perfil con las piernas dobladas a la manera oriental, tiene el brazo izquierdo extendido y la mano sobre el piso, mientras que de su pecho abombado sale un elemento no identificado, posiblemente el objeto que sujeta con el brazo derecho que queda oculto detrás de su cuerpo de perfil.

Las cuatro columnillas fueron transportadas al Centro regional INAH de Campeche, donde fueron restauradas por Diana Arano.

\section{Datos jeroglíficos}

El texto jeroglífico del frente de la banqueta sur está sumamente erosionado, por lo que nada se pudo identificar de los restos de trazos de escritura.

La banqueta del cuarto norte (Figura 2) contó originalmente con ocho bloques glíficos en su frente, dispuestos en cuatro grupos de dos bloques, con la siguiente disposición : bloques A-B de tinta negra sobre fondo verde, bloques C-D de tinta anaranjada sobre fondo azul, bloques E-F de tinta negra sobre fondo verde ; bloques G-H de tinta anaranjada sobre fondo azul. El bloque A está totalmente perdido, conservándose apenas restos de dos trazos de escritura. Los bloques B y Cestán mejor conservados, y los podemos transliterar y transcribir como

XV-[tu]-TUN-ni IX-[AJAW]

15 tum 9 Ajaw,

una fecha en el sistema de Cuenta Corta, que correspondería con 9.18.15.0.0 (805 d.C.).

Por su parte, el bloque D presenta la lectura

KAB'-WITZ

kab'witz 
Por su estructura, podría tratarse de una expresión toponímica. Sin embargo, el estado incompleto del texto - falta un bloque antes de la fecha y cuatro después de esta expresión - impide asegurar nada más. Sólo aventurar que podría tratarse de un topónimo que designe a la estructura 6 N2, al Grupo B o, lo que sería ciertamente interesante, al propio Río Bec.

El presunto topónimo estaría compuesto por kab' y witz, donde $k a b$ ' es una raíz polisémica que significa « tierra », « almagre, tierra roja » o « bajo, abajo » (Barrera 1980, p. 277) y witz significa « cerro » (ibid., p. 924). Un trabajador del proyecto, de habla yucateca, definió $k a b$ 'witz como el espacio que queda entre las colinas o elevaciones de terreno, posiblemente tomando $k a b$ ' en su acepción de « bajo ». Esta acepción está confirmada en las fuentes lexicas coloniales, donde se documenta cul cab uitz como « collado/colina/de sierra » (Álvarez 1980, p. 132), lo que sería quizá apropiado a la geografía del sitio, con numerosos bajos entre zonas elevadas.

De la banqueta oeste $\left(\mathrm{n}^{\circ} 3\right)$, la del salón posterior, tenemos cuatro fragmentos de piedras, hallados diseminados en el interior de la estructura. El fragmento codificado VC $\left(\mathrm{n}^{\circ} 1\right)$ conserva unos pocos trazos de escritura ilegibles. El fragmento VGAV ( $\mathrm{n}^{\circ} 2 \mathrm{~A}$ y $2 \mathrm{~B}$ ) es el más grande, resultado de la unión de dos fragmentos de losa. El texto constó originalmente de un bloque incompleto al principio y cinco bloques completos a continuación. Sin embargo, sólo es legible el primero de los bloques completos. El bloque pA se encuentra incompleto, conservándose únicamente su parte derecha, habiéndose perdido aproximadamente un tercio del total. En el bloque pB (Figura 8), pese a encontrarse algo deteriorado, podemos reconocer tres signos :

\section{IV-b'o-TOK'}

Posiblemente se trata de un nombre de persona, en el que podemos reconocer tres elementos : el número « cuatro », b'o y tok' « pedernal ». Con respecto a b'o, sugerimos relacionarlo con el nombre $B^{\prime}$ oh $b^{\prime}$ atestiguado como nombre de persona en otros textos clásicos, del que sería abreviatura : b'o, $B^{\prime} o\left[h b^{\prime}\right]$. Conocemos variantes de este nombre en otros textos, como IK'-b'o-b'o-TOK'/ IK'-b'ob'o-to-k'a, Ik' B'ohb' Tok' (Machaquilá, Estela 5, B3 ; Estela 6, A5 ; Estela 7, D4) y K'AN-b'o-TOK' / K'AN-b'o-b'o-TOK', K'an B'ohb' Tok' (Ek' Balam, Mural C Cuarto 29-sub y Texto Misceláneo 4). En otro caso, en la Estela 4 de Ixtutz, también aparece la secuencia b'o-b'o, $B^{\prime} o[h] b$ ', en contexto de denominación personal - un cautivo de Ajyaxjal B'aak, rey de Ixtutz. El personaje de Río Bec se habría llamado Chan B'o[hb'] Tok' o Kan B'o[hb'] Tok', dependiendo de cómo leamos el logograma IV « cuatro ", como CHAN, en cholano, o como KAN, en yucateco $^{2}$.

El fragmento de piedra $\mathrm{AA}\left(\mathrm{n}^{\circ} 3\right)$ presenta dos bloques glíficos en relativo buen estado de conservación, pudiéndose reconocer algunos signos aislados. 


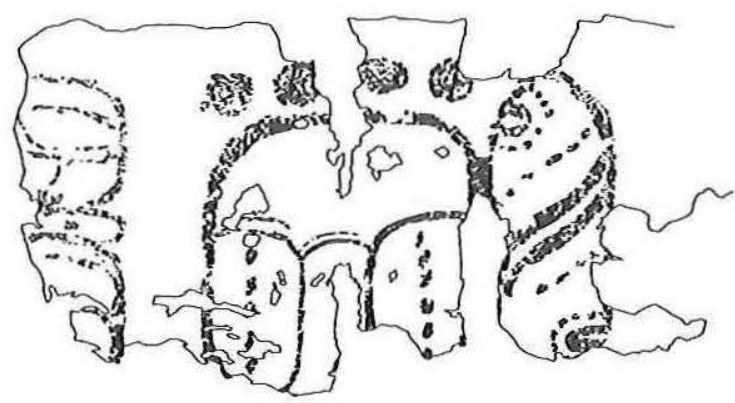

FIG. 8 - Entre los glifos de la banqueta oeste de $6 \mathrm{~N} 2$, piedra VGAV con, encima, el bloque glífico pB (Lacadena)

Estos signos, sin embargo, no hacen aún sentido, estando pendientes de análisis más profundos. En cuanto al fragmento $\mathrm{AN}\left(\mathrm{n}^{\circ} 4\right)$, apenas se conservan restos de pintura. Los trazos conservados del que sería el primer bloque corresponden a la expresión

\section{[yo]-[OTOT]}

yotoot

" la casa de »

Esta expresión es apropiada para el contexto en el que se encuentra, y posiblemente se refiere a la propia estructura $6 \mathrm{~N} 2$ del Grupo B.

En fin, por el estado de los glifos no es posible reconstruir el texto completo de las tres inscripciones. Ni siquiera es posible saber si el texto de las tres banquetas jeroglíficas era uno solo corriendo sobre los tres frentes, o si eran tres textos independientes. Lo que sí parece claro es que las tres banquetas pertenecen al mismo programa decorativo. Las columnillas de las banquetas norte y sur registran el mismo tema de escenas cortesanas ; la policromía es similar también en los tres frentes. Recordemos que, originalmente, el espacio de los tres cuartos delanteros de $6 \mathrm{~N} 2$ debió formar un salón único, con dos banquetas (norte y sur) y un amplio acceso a la banqueta (oeste) del salón posterior : este espacio fue probablemente concebido como espacio de corte, o parte especializada de función cortesana de la residencia $6 \mathrm{~N} 2$. Considerando que esta residencia y la vecina $6 \mathrm{~N} 1$ dominan el Grupo B, es factible atribuirlas a la familia del señor del Grupo B, cuyo nombre posiblemente fue Chan o Kan B'ohb' Tok', nombre de persona recuperado del fragmento $\operatorname{VGAV}\left(\mathrm{n}^{\circ} 2\right)$ de la banqueta oeste : podría haber sido el propietario u ocupante principal del edificio, aunque por el estado incompleto del texto no podemos asegurar este extremo; podría tratarse de cualquier otro personaje de la familia, o de un personaje relevante de la vida 
política del lugar. No hay Glifo Emblema asociado, pero no se puede hablar de su inexistencia debido al fragmentario estado de la inscripción.

La consideración de que las tres banquetas pertenecen al mismo programa único permite tomar la fecha conservada en la banqueta norte - 15 tuun 9 Ajaw (805 d.C.) - como la de dedicación de las otras y, por extensión, de la construcción de la estructura. Finalmente, es importante señalar que fechas de Cuenta Corta características del norte de Yucatán como la que aparece en la banqueta norte son escasas en Campeche del sur y en Petén.

\section{Comparaciones}

Las banquetas que presentan un nicho en la parte inferior son comunes en muchos sitios mayas, pero las banquetas con soportes colocados debajo del asiento para crear un espacio inferior vacío no son tan frecuentes. A estas últimas limitaremos nuestra breve reseña comparativa. Existen banquetas similares en la región de Río Bec, en Xpujil, en Becán (estructuras 5A y 5B) y en Manos Rojas (estructura 4 de MR.16, Nondédéo 2003, pl. 53), así como en Chicanná (véase más abajo). Fuera de la región, ejemplos publicados se conocen en Copán, Palenque y Piedras Negras ; en estos dos últimos casos, se han considerado como "tronos". Las banquetas de Copán se comparan bien con las de 6N2. En realidad, en Copán hubo numerosas excavaciones en residencias « de la élite no-real », o « noble », lo que podría explicar la frecuencia y la diversidad de las banquetas de forma y decoración muy elaboradas (pero véase también La Milpa, Hammond et al. 2000).

La banqueta con soportes quizás más conocida es la de la Estructura 82 del grupo 9N-8 de Copán (Baudez 1989 ; Webster y Abrams 1983, Fig. 4 ; Webster 1989, Fig. 14). Tiene cuatro pilares laterales y dos pilares centrales, todos de sección cuadrangular; que llevan esculpidos en bajo relieve seis personajes, cuatro $B a c a b$ (figura atlante) en los lados y dos personajes humanos en el medio, sentados de frente a la manera oriental, la cabeza de perfil, con tocados de plumas, parecidos a los personajes principales de las columnillas de la Estructura 6N2 de Río Bec ; la inscripción jeroglífica del ejemplo de Copán está esculpida en el canto de las piedras de orilla, e incluye un glifo que hace referencia a la " casa »; la fecha inscrita es 780 ; los relieves esculpidos llevan huellas de pintura de color rojo y azul sobre el estuco. La estructura constructiva general es comparable con la $6 \mathrm{~N} 2$ de Río Bec, excepto por los elementos laterales llamados plinths, que no existen en la $6 \mathrm{~N} 2$. Por lo tanto, la comparación es positiva en varios aspectos, si bien la banqueta de Copán es más grande y compleja que las de Río Bec.

También en Copán, la banqueta de la estructura $66 \mathrm{C}$ en el grupo $8 \mathrm{~N}-11$ presenta cuatro pilares rectangulares, que llevan esculpidos cuatro personajes, de 
los cuales dos son Bacab; el frente está pintado de anaranjado encima y debajo de la serie esculpida de supuestas representaciones del sol y de otros seres celestiales repartidos en nueve paneles yuxtapuestos (Webster et al. 1998, Fig. 11) ; no hay glifos ; también se fecha a finales del siglo VIII. Una banqueta del Grupo 9M-18 de Copán, erosionada, fechada en 780 , tiene ocho soportes tipo columnillas similares a las de la $6 \mathrm{~N} 2$ de Río Bec; el relieve esculpido en cada par de columnillas representa "...two atlantean figures, a death image and a Bacab emerging from a seashell » (Baudez 1989, p. 78 Fig. 71); los paneles del frente llevan glifos ; la construcción parece semejante a la de las banquetas de la 6N2 de Río Bec. Por lo demás, Webster $(1989$, p. 33) da una lista muy corta de banquetas jeroglíficas halladas anteriormente en Copán (ver también Baudez 1989, Fig. 69, banqueta jeroglífica con dos pilares del Grupo 10K-4, Copán).

En la estructura 22 de Chicanná, las dos banquetas laterales del Cuarto 2, cámara central a la que llegaba primero el visitante, al igual que en los casos de Copán, presentan cada una tres soportes, es decir una columnilla central con dos pilares laterales (Mayer 1999, Fig. 7 y 8). La decoración consiste, como en las demás banquetas de la 22, en dos medallones esculpidos y estucados (un rostro humano adentro de un motivo floral) en situación lateral, y dos anillos en relieve sobre la columnilla ; el frente quizás haya sido pintado originalmente.

Otras comparaciones no son tan específicas : señalemos la banqueta jeroglífica o « trono » del palacio subterráneo de Palenque (Baudez 1989, p. 76 Fig. 70) por sus dos pilares, aunque fechado en 9.11.0.0.0 (652); de Palenque también el soporte del "Trono Del Rio », o estela de Madrid, por el personaje central representado que Baudez (1989, p. 80 Fig. 72) considera como otra forma de Bacab. De Piedras Negras, la "banqueta-trono » del edificio J-6 (según Satterthwaite 1937) lleva glifos pintados y está fechada en 785 (Sharer 1994, Fig. 14.15).

Reents-Budet (2001), en su estudio de representaciones sobre cerámica de los ámbitos en los que se desenvolvían las « cortes reales », subraya la importancia de las banquetas y sugiere que muchas de las que aparecen ahora lisas estaban en realidad pintadas, con o sin glifos, al igual que las de la $6 \mathrm{~N} 2$ de Río Bec que estamos comentando. En cuanto a la configuración del espacio en los palacios, cabe observar que, a diferencia de las tres banquetas de la 6N2, en Copán las banquetas elaboradas se encuentran solamente en las cámaras centrales, mientras que no están decoradas (pero quizás pintadas) las banquetas de las cámaras laterales. Además, estos últimos cuartos abren directamente hacia el exterior, mientras que en la $6 \mathrm{~N} 2$ las dos cámaras laterales abren hacia adentro, dando al cuarto que llamamos «la antecámara ». Técnicas de decoración y contextos arquitectónicos no proporcionan más que algunos de los criterios de una tipología de banquetas que, debemos de admitirlo, sería todavía difícil lograr.

A pesar de todo, los ejemplos de Copán son los que se prestan más facilmente a comparación con los del Grupo B de Río Bec. Ahora bien, los grupos $9 \mathrm{~N}-8$ y 
$8 \mathrm{~N}-11$ de Copán corresponden a residencias de familias nobles, que no tenían estatuto real :

"...in non Western cultures, seats of authority may not be restricted to rulers alone » (Webster 1989, p. 31 ; véase tambien en La Milpa, donde las banquetas excavadas no corresponden todas a palacios reales, Hammond et al. 2000, p. 43 ; Noble 1999). Riese (1989, p. 88) indica que, en la inscripción de la banqueta de la Estr. 82 de Copán, el rey de Copán se encuentra mencionado, sin que tenga parentesco con el linaje del conjunto $9 \mathrm{~N}-8$.

De hecho, la asociación de personajes de rango no real con banquetas de mampostería no está limitada a La Milpa o Copán, como podemos ver por otros casos. En la interesante escena de K2914, por ejemplo, se representa, como dice el texto jeroglíico asociado, $u b^{\prime}$ aah yotoot « la imagen de la casa » de un personaje llamado Naah Ha'nal K'inich. Este personaje aparece sobre una banqueta de mampostería, rodeado de familiares, clientes y sirvientes - incluyendo un enano a los pies de la banqueta -, haciendo ostentación ante el espectador de su riqueza material (sacos de frijoles, mantas). Por el texto jeroglíico asociado sabemos también que Naah Ha'Nal K'inich no es el rey, sino un personaje de la nobleza al servicio del rey de Río Azul.

En contraste con los de Copán, los ejemplos de banquetas de la (hipotética) categoría «trono real » conocidos en Piedras Negras y Palenque no permiten hacer comparaciones directas con las banquetas de Río Bec, salvo a nivel de inscripciones glíficas y de representaciones antropomorfas.

Enfocando ahora no tanto la banqueta como estructura particular sino las escenas y motivos representados en los soportes de los tres ejemplos conocidos en el Grupo B de Río Bec, es posible aislar tres motivos que merecen un estudio comparativo : las escenas de corte en general, los enanos y las entidades sobrenaturales colocadas detrás del personaje principal.

Las escenas de corte confrontan generalmente a un personaje dominante con uno o varios personajes segundarios, quienes le presentan objetos como un espejo o un ramo de flores, comida o bebida. Es un tema común en vasijas cerámicas de figuras humanas (e.g. Reents-Budet 2001), mientras que no está documentado en esculturas, pinturas murales o grabados, con excepción quizás de pequeños objetos de jade que llevan el motivo del rey con enano (Schmidt et al. 1998, p. 252). La escena pintada en la vasija Kerr 1453 (Prager 2002, p. 49 Fig. 11) representa un buen ejemplo de una escena de corte que comprende varios elementos esculpidos en los soportes de 6 N2 de Río Bec : una banqueta con glifos pintados en la misma posición que los de $6 \mathrm{~N} 2$, dos enanos, uno presentando un espejo « al rey », el otro bebiendo un líquido de una escudilla, un viejo jorobado, entre otros personajes y elementos. El rey lleva un taparrabo, un collar de cuentas $\mathrm{y}$ un tocado de plumas.

Para la clase general de iconografía cortesana, Reents-Budet propone un listado de escenas comunes en las vasijas, entre las cuales las de « recepción de 
tributos y regalos » y de " banquetes en la corte » parecen describir adecuadamente las escenas esculpidas en las banquetas de 6N2 (ibid., p. 213). Sin embargo, las escenas de Río Bec carecen de un elemento frecuente en las vasijas pintadas, a saber el tributo figurado (probablemente) por las ollas o canastas llenas, o los bultos amarrados de mantas, colocados delante " del rey ", debajo de su banqueta. Quizás no sea necesario dar significado a esta ausencia en el caso de Río $\mathrm{Bec}$, ya que las columnillas no ofrecen mucho campo para representar los varios aspectos de la vida cortesana (la vasija Kerr 1453 ya señalada combina los motivos de intercambios diversos, del tributo y aún de la ofrenda musical). En cualquier caso, de tener significado la ausencia de elementos de tributación en las escenas representadas en las columnillas de las banquetas de la 6N2 de Río Bec está posiblemente indicando que la actividad cortesana era la principal allí realizada.

En cuanto al motivo del enano, mencionamos que pertenece a la iconografía cortesana, pero además, es conocido en la iconografia político-ritual de las estelas esculpidas de Caracol, Tikal, Dos Pilas, Calakmul, Xultún, El Perú... entre otros sitios (Coggins 1994; Prager 2002). Los enanos, de los cuales hay más de 200 ejemplos conocidos en la escultura maya (Prager 2002), están representados al lado del rey, llevando un vestido adornado ; en la estela 31 de Yaxhá y la 6 de Aguateca, el enano está sentado ; los tocados son similares al del enano de la 6N2 en el caso de la estela 14 de Dos Pilas y del dintel de la estructura 5D-52 de Tikal (Coggins op. cit., Fig. 18, 17 y 15 ; Prager op. cit., Fig. 3).

Las representaciones de la entidad sobrenatural que figuran en tres de los soportes de las banquetas de $6 \mathrm{~N} 2$ en Río Bec evocan la ave solar nocturna de los monumentos 23 y 24 de Quiriguá que, según Baudez (2002, p. 185 Fig. 1.51), simboliza al sol diurno y al rey vivo naciendo de la tierra ; la nariz encorvada, el tocado y el elemento saliente arriba del ojo son semejantes. Otra comparación es posible con la ave que aparece de perfil sobre dos paneles laterales, uno en cada extremo de la banqueta de la Estr. $66 \mathrm{C}$ del Edificio $8 \mathrm{~N}-11$ en Copán (Webster et al. 1998, Fig. 11A) ; se notan de nuevo el mismo pico encorvado y el elemento saliente a nivel del ojo, vistos de perfil ; hay que observar que estas dos aves miran hacia el exterior de la banqueta, mientras las de $6 \mathrm{~N} 2$ miran hacia dentro. Los autores los comparan con los pájaros extremos de la banda-cielo de la estela 32 de Piedras Negras (ibid., p. 332 Fig. 11B).

Para concluir esta breve reseña comparativa, nuestra propuesta preliminar es que las banquetas de la 6 N2 del Grupo B de Río Bec pertenecen a una categoría específica caracterizada por un espacio inferior vacío amplio, soportes del frente que llevan iconografía y, encima de ellos, el frente con texto glífico. Esta categoría todavía está poco documentada e ilustrada, habiéndose identificado solamente unos cuatro o cinco ejemplos en Copán y quizás en Chicanná. Se trata de asientos de autoridad colocados en la cámara central de entrada de palacios de la nobleza, construidos aparte de los palacios reales y, por lo tanto, desconectados del ámbito 
del poder real (sin perjuicio de las relaciones personales entre individuos). El caso de la $6 \mathrm{~N} 2$ ilustra bien estos rasgos, pero con matices que merecen ser subrayados : - en la $6 \mathrm{~N} 2$, son en realidad tres cámaras las que contienen este tipo de banquetas y no sólo una, siendo abiertas las tres sobre una antecámara común, de tal modo que los visitantes a cualquier de las cámaras debían de tomar en consideración los ocupantes de las demás cámaras ; este dispositivo con tres banquetas decoradas no es tan frecuente en los palacios mayas (fuera de Río Bec); por lo demás, obviamente las tres cámaras estában jerarquizadas y, al igual que en Copán, la central era la que dominaba ;

- el tema de la iconografía de la $6 \mathrm{~N} 2$ no refleja un complejo conocimiento cosmogónico como en el caso de las esculturas de Copán (véase Baudez 1989); e.g., si bien la representación antropomorfa es importante en ella, no aparece el tema del cargador del mundo, Bacab, o figuras atlantes; el tema de las escenas de corte de la $6 \mathrm{~N} 2$ es muy común en la cerámica de la cultura maya clásica y no mobiliza más que personajes de convención que forman parte de las representaciones elitistas, e.g. viejo jorobado y enano; aun el ser sobrenatural incluido en la iconografía de $6 \mathrm{~N} 2$ es representado de un modo sumamente esquemático, sin detalle y con muy pocos rasgos que permitan identificarlo. El énfasis puesto en Copán en elementos cosmogónicos en contraste con el énfasis puesto en Río Bec en aspectos mundanos cortesanos puede estar hablándonos precisamente de los ocupantes de las banquetas, los dueños en definitiva de los edificios en que se encuentran : en Copán, hay certeza por las inscripciones de las banquetas de que algunos de los dueños de las banquetas son ajk'uhu'n del rey, cargo éste relacionado en muchas ocasiones con actividades rituales, quizá sacerdotales; esto explicaría la recurrencia de los motivos de bacabes ; por su parte, el dueño de la 6N2 de Río Bec sería un personaje perteneciente a la nobleza política local ;

- parte de la " decoración » (usando este término con cautela ya que tiende a reducir una realidad más compleja) de las banquetas de $6 \mathrm{~N} 2$ es pintada y no esculpida; es probable que muchas banquetas de residencias elitistas en las ciudades mayas hayan sido pintadas de misma manera y hayan perdido su repello pintado ; esto limita el trabajo de comparación y la pertinencia de la categoría de «banqueta jeroglíica ».

\section{CONCLUSIÓN GENERAL}

Las banquetas son tan frecuentes en los contextos residenciales y palaciegos mayas, incluyendo las banquetas de madera representadas en pinturas o relieves, que se hace imprescindible construir una tipología de ellas con vistas a su interpretación funcional así como socio-política. Los tres casos de la 6N2 en Río Bec aportan varios datos, que apuntan hacia cierta complejidad funcional. En realidad son seis ejemplos, tomando en cuenta las cinco banquetas de $6 \mathrm{~N} 1$ (contando las de los cuartos laterales), edificio vecino de $6 \mathrm{~N} 2$. 
Aquí, es importante reflexionar sobre el hecho que las banquetas más elaboradas del Grupo B no se encuentran en el edificio $6 \mathrm{~N} 1$ de dos torres, supuestamente el más prestigioso, sino que en el « palacio » $6 \mathrm{~N} 2$ vecino. En $6 \mathrm{~N} 1$, las tres banquetas del cuerpo central son idénticas a las de $6 \mathrm{~N} 2$ morfológicamente (aunque, de nuevo la central no es más que un piso interior sobreelevado) y quizás sus piedras frontales estaban pintadas originalmente. Pero una diferencia, a la que el estudio comparativo da una gran pertinencia, es que ninguna tiene un espacio inferior vacío y, por lo tanto, tampoco tiene soportes. Esta diferencia sugiere que las funciones de recepción de $6 \mathrm{N1}$ y $6 \mathrm{~N} 2$, que sus cuerpos centrales tenían obviamente (siquiera por sus dimensiones y por los grandes vanos de puerta), se deben de distinguir una de otra.

Si bien son muchos los rasgos que pueden diferenciar una categoría de « recepción » de otra (identidad de los visitantes, ocasiones de las visitas, tipos de interacción social...), al menos dos elementos de las banquetas de $6 \mathrm{~N} 2$, es decir el espacio inferior y el tema decorativo de los soportes, sugieren que, en $6 \mathrm{~N} 2$ y no en $6 \mathrm{~N} 1$, el visitante era un individuo siempre inferior al personaje sentado en la banqueta, del que se esperaba un comportamiento de cortesano, en interacciones de la vida cotidiana que incluían cierta familiaridad (presentación del espejo), intercambios de comida (banquetes), conversaciones (el jorobado) y posiblemente también presentación de tributos. Estos últimos no están figurados en los soportes, pero se puede suponer que la demanda de ellos era fuertemente sugerida al visitante por el espacio inferior vacío de la banqueta, en el que se solía colocar regalos y tributos (Pereira y Michelet s.d.). Eran otras las clases de recepción de visitantes que se desenvolvían en los dos salones centrales de 6N1.

En fin, nos parece también pertinente subrayar el hecho que los datos reunidos a la fecha en el Grupo B de Río Bec después de dos temporadas de excavaciones intensivas (Michelet et al. 2003) no lo califican de ninguna manera como espacio residencial o político de un « rey ». El Grupo B fue uno más de los complejos residenciales de la zona arqueológica de Río Bec, ni siquiera el más importante desde el punto de vista arquitectónico (véase Nondédéo et al. 2003). A primera vista y $\sin$ perjuicio de lo que las próximas temporadas podrían aportar al tanto, los datos que proporcionan las banquetas del palacio $6 \mathrm{~N} 2$ y las pistas que abren se refieren a una sociedad en la que dominaban familias nobles, o al menos familias social y económicamente potentes, que fueron bastante autónomas cada una en el marco de su territorio, de su comunidad y de su conjunto residencial.

\section{NOTAS}

1. Proyecto del CNRS, UMR Archéologie des Amériques (París), desarrollado en el marco del Cemca, Centro francés de estudios mexicanos y centroamericanos (México), iniciado en 2002, bajo la responsabilidad científica de Dominique Michelet y Marie-Charlotte Arnauld, con financiamiento del 
ministerio de Asuntos exteriores de Francia, del CNRS, de Empresas francesas en México, de SEDESOL (a través del INAH), y con apoyo logístico de la compañia CiMESA.

2. En el Norte de Yucatán - en Ek' Balam, M96 - se documenta en una ocasión el numeral " cuatro » escrito como ka-na, $\mathrm{kan}$, lo que reflejaría la forma lingǘstica yucateca. No contamos todavía con suficiente información sobre Río Bec para saber cuál era la lengua vernácula del sitio o determinar con seguridad la lectura posible del logograma.

\section{REFERENCIAS CITADAS}

Álvarez C.

1980 Diccionario etnolingüistico del Maya yucateco colonial. 1. Mundo Físico, UNAM, México D. F.

Barrera Vúsquez A.

1980 Diccionario Cordemex. Maya-Español. Español-Maya, Ediciones Cordemex, Mérida.

BAUDEZ C.-F.

1989 "The House of the Bacabs : an iconographic analysis ", in D. Webster, ed., The house of the Bacabs, Dumbarton Oaks Research Library and Collection, Washington, pp. 73-81.

2002 Une histoire de la religion des Mayas, Albin Michel, Paris.

Coggins C. C.

1994 "Man woman and dwarf», Memoria del primer congreso de mayistas, 3, pp. 2872, UNAM, México.

Hammond N., G. Tourtellot, G. Everson, K. L. Sagebiel, B. Thomas y M. Wolf 2000 "Survey and excavation at La Milpa, 1998 », Mexicon, XXII (2), pp. 38-45.

Michelet D., E. Taladoire, S. Dzul, P. Nondédéo, J. Patrois, M.-C. Arnauld, A. Cantero, P. Becquelin, R. Acosta, E. González, D. Arano, A. LacaDENA, D. Galop y B. VANnière

2003 Rio Bec, Campeche. Informe de la segunda temporada del 27 de marzo al 25 de mayo de 2003, CNRS, Paris/CEMCA, México.

MAYER K. H.

1999 "Bench decorations of structure XX, Chicanna, Campeche ", Baessler-Archiv, Neue Folge, XLVII, pp. 323-343.

NoBLe S.

1999 Maya seats and Maya seats of authority, Ph.D. Dissertation, University of British Columbia, Vancouver.

NONDÉDÉO P.

2003 L'Évolution des sites mayas du Sud de l'État du Campeche, Mexique, Archaeopress, Oxford, coll. "British Archaeological Reports, International series 1171/Paris monographs in American archaeology » 12. 
Nondédéo P., D. Michelet, M.-C. Arnauld, E. Taladoire, J. Patrois y R. Barrois

2003 "Río Bec: primeros pasos de una nueva investigación », Mexicon, XXV (4), pp. 100-105.

Pereira G. y D. Michelet

s.d. «Gobernantes mayas en lechos de muerte : el caso de Balamkú, un patrón funerario del Clásico temprano ", in Culto funerario en la sociedad maya. Actas de la IV Mesa Redonda de Palenque, INAH, México [en prensa].

Prager C.

2002 « Enanismo y gibosidad : las personas afectadas y su identidad en la sociedad maya del tiempo prehispánico », in V. Tiesler, R. Cobos y M. Greene Robertson, eds, La organización social entre los mayas prehispánicos, coloniales y modernos. Memoria de la tercera mesa redonda de Palenque, CONACULTA/INAH, México, vol. 2, pp. 35-67.

RIESE B.

1989 "The inscription of the sculptured bench of the House of the Bacabs ", in D. Webster, ed., The house of the Bacabs, Dumbarton Oaks Research Library and Collection, Washington, pp. 82-87.

ReEnTs-Budet D.

2001 «Classic Maya concept of the royal court», in T. InOmata y S. D. Houston, eds, Royal courts of the Ancient Maya, Westview press, Boulder, Co, vol. 1, pp. 194233.

SATterthwaite L.

1937 «Thrones at Piedras Negras », University Museum Bulletin, 7 (1), pp. 18-23.

Schmidt S. P., M. de la Garza y E. Nalda

1998 Maya, Bompiani, Venezia.

SHARER R. J.

1994 The ancient Maya, Stanford University Press, Stanford.

STUART D.

2000 "Las nuevas inscripciones del Templo XIX, Palenque ", Arqueología Mexicana, VIII (45), pp. 28-33.

WEBSTER D.

1989 "The House of the Bacabs : its social context », in D. Webster, ed., The house of the Bacabs, Dumbarton Oaks Research Library and Collection, Washington, pp. 5-40.

Webster D. y E. M. Abrams

1983 " An elite compound at Copan, Honduras », Journal of Field Archaeology, 10 (3), pp. 285-296.

Webster D., B. Fash, R. Widmer y S. Zeleznik

1998 « The Skyband Group : investigations of a Classic Maya elite residential complex at Copán, Honduras », Journal of Field Archaeology, 25 (3), pp. 319-343. 